\title{
The Interactive Role of Dynamic Capabilities in View of The Relationship Between Complexity Management and Performance Strategic E: A Survey in A Sample of Private Colleges
}

\author{
Muthana Zahim Faisal, Prof. Dr. Nadhumm Jawad Abid Al- Zeidi \\ College of Administration and Economics / University of Baghdad
}

DOI: $10.37648 /$ ijrssh.v10i04.025

Received: $1^{\text {th }}$ November, 2020; Accepted:01 ${ }^{\text {st }}$ December, 2020; Published: 03 ${ }^{\text {rd }}$ December, 2020

\section{ABSTRACT}

The research aims to test the relationship and impact of complexity management and its dimensions as an independent variable in strategic performance and its dimensions as a responsive variable, through dynamic capabilities and its dimensions as an intermediate variable, in some private colleges, and based on the importance of the subject of research, the researcher depended the descriptive analytical approach in the completion of his research which dealt with a Random sample class number (143) individuals, representing the sample of research, represented by the senior leaders of the research faculties, depended the questionnaire as a main tool in the collection of data, and used a set of appropriate statistical methods for research to test the hypothesis, the most prominent results of the research were to prove the validity of the main hypothesis embodied the impact of complexity management directly and indirectly by strategic performance, and the impact is high in the case of the intermediate dimensions of dynamic capabilities, and the dynamic capabilities contribute to reducing the levels of complexity management and strategic performance in the private colleges, and the most prominent recommendations were the need for the research faculties to pay attention to the variables of research, especially the complexity management and strategic performance of the effects they cause through the renewal and diversification of activities and tasks carried out by colleges and the elimination of routine activities in the work by investing in the opportunities available to them). As well as identifying what search variables are Its and negative effects and how to eliminated or reduce it, and to understand the concept and importance of dynamic capabilities and their sub-dimensions on the variables of the research and the And the advantages it has for colleges sample research.

Keywords: Complexity Management, Strategic Performance, Dynamic Capabilities, Interdependence, Diversity Management, Uncertainty.

\section{INTRODUCTION}

The contemporary business environment has undergone significant and rapid changes in the past few decades, which have had a significant impact on the competitive scene and have affected the success, survival and sustainability of organizations. The environment of organizations (colleges) has become more complex and dynamic at the local and global levels, forcing significant challenges to organizations Located in this environment, 
(IJRSSH) 2020, Vol. No. 10, Issue No. IV, Oct-Dec

and Iraqi organizations are not isolated from those changes, which has imposed a set of challenges that require them to invest their existing resources and capacities and to detect new resources to be able to renew and revitalize their strategies to ensure that they are adapted to their environment, rapid respond to their requirements and ensure that their outcomes are consistent with the actual needs of society. Moreover, the theory of complexity suggests that when dealing with unpredictability, managers need to involve contrary forces to the system and chaos in order to guide emerging outcomes. The implications for managers are far-reaching but not entirely new. We note that dimension the uncertainty has always been a feature of the business environment. Today's businessmen, managers and leaders need not only the skills to operate in an unstable and unpredictable environment, but also to understand causes. In the 21 st century, management science is facing a dual paradigm transformation. The first transformation of the organization is seen as a multi-cultural socio-cultural unit (different from mechanical and biological vision), which affects and affected the environment (perception of the organization's systems). The second transformation helps to better understand the complexity of reality (Skarzăauskiene,2010:50).

(Augier \& Teece,2009:411) in terms of the dynamic capabilities of executives stated that they would play a crucial role within organizations, as they were expected to "sense and seize" new opportunities and reconfigure them when change occurred. This necessitated the allocation, Reconfigure, installation and regrouping of the Organization's resources and assets, which (Teece,2007) considered the main strategic functions of (CEOs). Recognized as the best performance in their organizations (tong \& Arvey,2015:666). For sustainable strategic performance, organizations are always looking for new ways(Niu,2014), The impact of dynamic capabilities on the strategic performance of organizations often has multiple pathways, the first is that dynamic capabilities directly affect strategic performance, and the second is other variables affecting strategic performance across dynamic capabilities as a mediator, And assume (Anand,2001) that dynamic capabilities enable organizations to select more credible partners and make their relationships more effective, so that new knowledge can be gained to improve their performance (Lin, 2018:81).
e-ISSN: 2249-4642, p-ISSN: 2454-4671

\section{THE FIRST TOPIC IS THE THEORETICAL ASPECT}

\section{First: Managing the complexity of private business organizations}

Organizations are seen as basically complex systems, Management can be understood in this context that having inclusion of the complexity of designing, activities and objective oriented relationships and unit development (Edgeman, 2019:4). In order to organizations remain competitive, have shifted the focus of their strategies to cost management, quality and technology to leading innovative services. As a result, innovative services are gradually emerging in the unique sales offers of organizations in response to the dynamic, competitive and complex environment (Bullinger et al., 2003). At the same time, organizations need to maintain their constantly developing service market, always being "one step ahead of their competitors" to ensure they can meet the requirements of customers (Kryvinska et al., 2014:1). Organizations are also forced to involve a wider range of stakeholders because social and environmental factors overlap with business issues and by borrowing from systems theory, sociologists have realized since the 1950s that organizations as open systems are subject to environmental forces. However, the focus was to "solve problems" and plan, maintaining organizational balance by controlling negative reactions(Tong \& Arvey,2015:54).

So far, business task analysis has proved very costly, It is largely limited to the complex tasks required by organizations, such as military organizations, which require the training of large numbers of new military personnel to operate very complex equipment in a short period of time. However, as learning more, it is expected that new methods and techniques will make it easier to analyze and then automate the most complex tasks in most organizations (Brocke \& Rosemann, 2015:74).

Thus, the complex environment invite organizations to be complex systems capable of delivering high levels of adaptation through learning and emerging behaviours (Davila et al., 2012:14). And in principle, the complexity of customer participation in the service delivery process has become more difficult for front-line staff when customers are heavily participated in the service delivery process (Dong et al., 2015:173), so services involving more intensive customer participation, such as health care or education, are more complex than those with low interaction between front-line staff and customers, such as 
(IJRSSH) 2020, Vol. No. 10, Issue No. IV, Oct-Dec

fast-food restaurants or auto repair services (Kostopoulos ,2019:41).

Complexity management is an essential feature of organizations. The complexity may arise from many factors, including different contextual factors, interrelated elements, the use of advanced technology, and the need for customer-provider interactions. The service systems were known by Reim et al., 2015:62, as very difficult presentations in terms of the degree of conditioning, concentration of operations and importance for business (Zou et al., 2019:7). (Maier, 2009:5) reported that the concept of complexity management arise from systems theory to illustrate the difficulty of understanding system management because of its elements and coherence, and noted that the definitions of complexity and order were remarkably similar. The system is defined as a set of different elements related to the performance of a unique function that cannot be carried out by the elements alone, and complexity is defined as a property consisting of interrelated or interlocking parts (Antinyan et al., 2019:14).

(Yates,1978) provides a practical definition that combines Various aspects of complexity across disciplines and defines the complex system as a system that presents one or more of the following features: "large interactions, many constituent parts or interactions, nonlinear, break-in, and non-economic constraints" (Wiengarten et al., 2017:4). (Simon,1962:468) defines the complex system as "a large number of parts that interact in a non-simple way." The number of interrelated parts increases coordination requirements, the understanding of complexity borrows from the Theory (Kaufmann,1993) of complex adaptive systems (Lamarche \& Maillet,2016:839), in which the complexity of the system depends positively on the number of interconnections between elements within the system (Snihur \& Tarzijan, 2017:4).

\section{Second: dynamic capabilities:}

Dynamic capabilities are based on the concept of resource-based vision (RBV), It is assumed that the organization's success result from its activity and resource management, and this theory assumes that organizations can gain a sustainable competitive advantage by possessing resources with characteristics that may be material (e.g. capital), human (e.g. staff skills), or organizational (e.g. formal and informal planning), which are valuable, rare, unchangeable (Karimi-Alaghehband \& Rivard,2020: 2).

\section{e-ISSN: 2249-4642, p-ISSN: 2454-4671}

The organization's dynamic capabilities arise from members of the organization if they are empowered in their discourse and work and if they are united in their goals and style. The identity of the organization determines the direction of the organization. A conscious organization takes care of its members by allowing their voices to be heard, as well as taking information and signals that flow from the lower level, from other parties and from the external environment (Dutta, 2019:9). (Giudici and Reinmoeller,2012) states that research on dynamic capabilities needs clarity in definitions in order to prevent reincarnation and build additional knowledge (Furnival et al., 2019:6).

Dynamic capability theory attempts to explain the problem that is proportional with the regulatory capabilities of the external environment, and the researchers have introduce a number of dynamic capabilities that can help build the organization, and are constantly able to improve market-based competitive capabilities through repair methods, reproduce capabilities in the new competitive market through creative demolition, and continue to enhance and rebuild the organization's skills and resources to adapt to the changing environment (Meng \& sun). ,2019:509). The organization's performance is determined by its ability to access resources and use them to adapt to their business environment (Bleady et al.,,2018), which consisting of complex coordination and unique knowledge that becomes an important capital for well-organized management (Rusydi et al.,2019:89.(

The dynamic capabilities involve high-level activities that enable the organization to upgrade its normal capabilities and direct its activities towards high gains, requiring the development, coordination and measurement of the organization's resources to deal with and changes in the business environment Reconfigure them can allow the organization to achieve higher profits by developing different services that deal with new markets, or existing markets in new ways (Teece, 2016:31). Interest in dynamic capabilities arise from its potential impact on competitive advantage, the organization is said to have a competitive advantage when it achieves greater success than current or potential competitors in its industry, and in line with this perception, the performance of organizations superior to competitors is usually a practical indicator of competitive advantage (schilke, 2013:180).

Dynamic capabilities are usually seen as their organization's ability to deal with a changing business environment in order to survive and maintain competitive 
(IJRSSH) 2020, Vol. No. 10, Issue No. IV, Oct-Dec

advantage. They represent strategic capabilities for the integration and reordering of internal and external resources in response to the changing environment (Darawong, 2018:2). In order to respond to these changes, organizations need to adapt to them quickly and efficiently, by building and renewing capabilities and competencies, and they can be considered final organizational capabilities conducive to long-term performance, so that dynamic capabilities, and the competitiveness of the organization, are determined by three factors (Deya, 2016:38): 1. Strategic pathways, which indicate the availability of a range of strategic options for the organization. 2. Situation to the organization's resources, which refers to tangible assets. 3. Organizational processes which Associated with management skills, behavior patterns, thinking and learning.

\section{Third: Strategic performance}

Performance is a contextual concept linked to the phenomenon being studied, and in the context of the organization's financial performance, performance is constitute a measure of changing the organization's financial situation, Or the financial results resulting from management decisions and the implementation of those decisions by the members of the organization, since these results are contextual Visualizations, the indicators used to represent performance are selected based on the situations of the organizations that are take care of, and the selected indicators represent the results achieved, good or bad (Carton, 2006:3). The first reason for the ambiguity of performance lies in the multidimensional construction, which must be defined exactly, in order to measure its relationship to the direction of the market, while the second reason is because of the different characteristics affecting the nature of the works that make it difficult to evaluate and confirm the results of the measurement. (Sundström \& Ahmadi, 2019:1)

(karuhanga,2015:2) reviewed the literature of strategic performance in order to identify main strategic aspects, so performance in The Oxford Advanced Dictionary Defined that any action taken, as performance is known as the actual end result of the activity, the specific objective of the activity, compared the actual results with the desired final results, and was able to make the necessary corrections to improve its performance (Khaireddin et al.,2015:291).

(Abdul Majid, 2016:1) emphasized that strategic performance often requires multiple tasks simultaneously, sequentially or mutually achieved through partnerships
e-ISSN: 2249-4642, p-ISSN: 2454-4671

between organizations, leading to success in achieving strategic objectives, strategic performance representing the organization's competitiveness capabilities, covering the organization's most influential position among competitors for a foothold in the market, increasing organization awareness and responding to competitive challenges created by competitors, strategic performance Determines the organization's goals, innovation capacity, and contributing to Financial aspects. (Schütz et al., 2019:11). It focuses on the long-term value of competitors by using excess residual income or cash flow, as organizations choose to measure strategic performance because they enable them to use qualitative measure to increase their competitiveness in the market (Hassan et al., 2016:47). According to dong et al., 2013:601, strategic performance is a useful measure as it reflects the performance of the organization or business and It takes into account market volatility and trends. Therefore, a shared vision among (CEOs) has been generated that constantly changing the organization's business environment is the result of responding to the pressures of global competition, technological developments that are occur due to the communications revolution, alliances and economic liberalization between nations, which have made the lives of organizations more difficult than ever . Changes in the business environment confirm the need to create value and develop competitive advantages and sustain them (yadav \& Sagar, 2013:947).

Scientists focused primarily on publishing strategic performance measures, rather than on strategic employment because of their long-term effects, they implicitly assuming meaningful methods and approaches to generate organizational advantages (Pollanen et al., 2016:1). Therefore, measuring strategic performance helps (CEOs) and other stakeholders to identify and achieve their strategic goals, plans and decisions, although the book's views differ on measuring it as a means of achieving, implementing and reformulating the strategy, communicating with main objectives and priorities of organizations as well as providing strategic alignment, improving the support process, encouraging progressive innovation, and bridging the strategic gap between vision and business management, as many organizations seek to measure performance systematically and comprehensively, while some measure it unplanned methods, with reference to the existence of methods. Traditional and modern (oyewobi et al., 2015:110). 


\section{THE SECOND RESEARCH METHODOLOGY}

\section{First: search problem}

The main problem arises in how the basic elements of research are Interactive understood and applied in a sample of private colleges to gain customer satisfaction and generate value and differentiation, in addition to unifying social and environmental interests in their environmental processes and interactions and on a voluntary basis with regard to the perspective of social responsibility for achieving strategic performance, so the main problem of research focuses on following question: (What is the interactive role of dynamic capabilities In view of the relationship between complexity management and strategic performance).

\section{Second: The hypothetical chart of search}

In view of the theoretical framework and the researcher's introducing to the research problem, the researcher developed an explanatory chart of the researched idea, as the hypothetical chart embodies the expected relationship between the dimensions of the research sample and the statement of solutions and objectives, as well as the possibility of measuring the impact of any variable individually or societally. Hence the statement expected result, as illustrated by Figure 1.

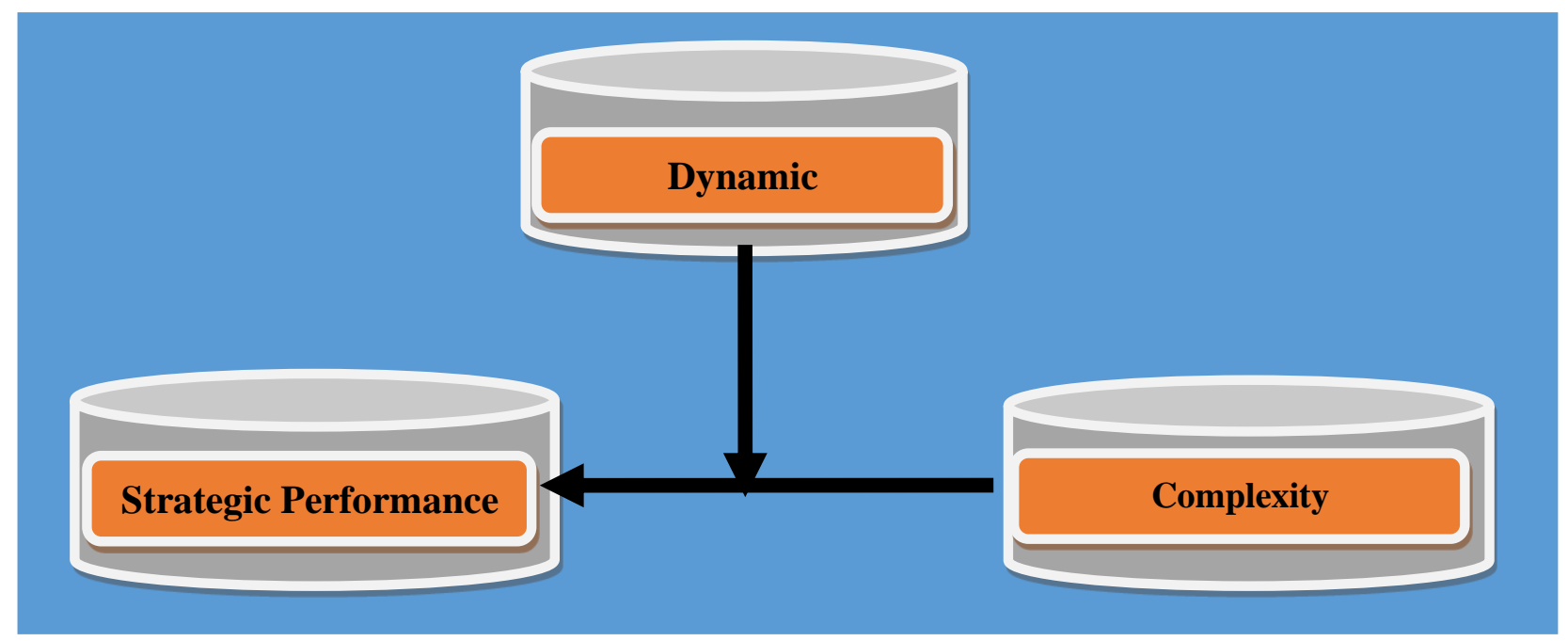

Third: The main research hypothesis

Figure 1: Research Model

Dynamic capabilities mediate the relationship between complexity management and strategic performance of statistical importance, as this hypothesis represents only the mediation role as mentioned earlier in the research hypotheses.

\section{THE THIRD TOPIC IS THE PRACTICAL ASPECT OF RESEARCH}

\section{First: Descriptive statistics of search variables}

This paragraph is specialized in presenting the results of the statistical description of the search variables in view of statistical analysis tools and at the level of description, which are each of the measures of dispersion, which represented of the standard deviation and the coefficient of difference, on the basis of which the relative importance of each paragraph of the scal of the search determined reaching to the research dimensions and for each of the three variables expressed in the search, and the measures of centrality, which represented in the mathematical medium of the answers of the sample for each paragraph and each dimension of dimensions of the variables. The descriptive Statistics also included a determination of the relative importance of each paragraph by distributing the arithmetic medium for each paragraph of the category to which it belonged, and in accordance with the five Likert scale, where the answer levels were divided by five categories formed by extracting the range 
between the upper and lower limits of the scale $(5-1=4)$, then dividing the output by the highest value $(4 \backslash 5=0.80)$ scale) and then adding the output to the minimum limit and According to the following division.

1. Description of the variable of complexity management and analysis it according to sample responses :

As an independent variable, this interpreted variable included three dimensions: interdependence, diversity management, Uncertainty, and table 1, which shows the results of these dimensions and their paragraphs:

Table (1) Results of descriptive statistics of complexity management variable

\begin{tabular}{|l|l|l|l|}
\hline Sub-dimensions & $\begin{array}{l}\text { Arithmetic } \\
\text { medium }\end{array}$ & Standard deviation & $\begin{array}{l}\text { Coefficient } \\
\text { Variation }\end{array}$ \\
\hline Interdependence & 3.7622 & $\mathbf{0 . 6 5 2 6 0}$ & $\mathbf{0 . 1 7 3 4}$ \\
\hline Uncertainty & $\mathbf{3 . 6 6 7 1}$ & $\mathbf{0 . 5 5 3 5 8}$ & $\mathbf{0 . 1 5 0 9}$ \\
\hline Diversity Management & $\mathbf{3 . 8 2 5 2}$ & $\mathbf{0 . 5 4 9 4 5}$ & $\mathbf{0 . 1 4 3 6}$ \\
\hline
\end{tabular}

2. Description of the variable dynamic capabilities and analyze it according to sample responses :

Dynamic capabilities represent an interactive variable, this variable has been measured through five dimensions (environmental sensing capabilities, opportunity Seize capabilities, Reconfigure capabilities, marketing capabilities, technological and educational capabilities), the following table (2) shows the most important results of the statistical description of each dimension.

Table (2) Results of metadata of dynamic potential variable

\begin{tabular}{|l|l|l|l|}
\hline Sub-dimensions & $\begin{array}{l}\text { Arithmetic } \\
\text { medium }\end{array}$ & $\begin{array}{l}\text { Standard } \\
\text { deviation }\end{array}$ & $\begin{array}{l}\text { Coefficient } \\
\text { Variation }\end{array}$ \\
\hline Environmental sensing capabilities & $\mathbf{3 . 5 3 6 1}$ & $\mathbf{0 . 5 9 2 4 5}$ & $\mathbf{0 . 1 6 7 5}$ \\
\hline Opportunity Seize capabilities & $\mathbf{3 . 6 7 1 3}$ & $\mathbf{0 . 6 0 2 8 6}$ & $\mathbf{0 . 1 6 4 2}$ \\
\hline Reconfigure capabilities & $\mathbf{3 . 4 8 9 5}$ & $\mathbf{0 . 5 9 2 4 7}$ & $\mathbf{0 . 1 6 9 7}$ \\
\hline Marketing capabilities & $\mathbf{3 . 5 9 0 9}$ & $\mathbf{0 . 5 6 5 2 7}$ & $\mathbf{0 . 1 5 7 4}$ \\
\hline Technological and educational capabilities & $\mathbf{3 . 5 4 3 4}$ & $\mathbf{0 . 5 8 2 2 4}$ & $\mathbf{0 . 1 6 4 3}$ \\
\hline
\end{tabular}

3. Description of variable of strategic performance and analyze it according to sample responses :

Strategic performance embodies the role of the responsive variable, which is measured by five dimensions, and the following table(3) shows the most important results of the statistical description of each dimension.

Table (3) Results of descriptive statistics of the strategic performance variable

\begin{tabular}{|l|l|l|l||}
\hline Sub-dimensions & $\begin{array}{l}\text { Arithmetic } \\
\text { medium }\end{array}$ & $\begin{array}{l}\text { Standard } \\
\text { deviation }\end{array}$ & $\begin{array}{l}\text { Coefficient } \\
\text { Variation }\end{array}$ \\
\hline Financial Perspective & 3.5047 & $\mathbf{0 . 6 2 7 9 7}$ & $\mathbf{0 . 1 7 9 1}$ \\
\hline Customer Perspective & 3.7238 & $\mathbf{0 . 6 0 3 2 3}$ & $\mathbf{0 . 1 6 1 9}$ \\
\hline Internal Process perspective & 3.7343 & $\mathbf{0 . 5 9 6 7 6}$ & $\mathbf{0 . 1 5 9 8}$ \\
\hline Learning and Growth Perspective & $\mathbf{3 . 9 6 1 5}$ & $\mathbf{0 . 4 7 2 9 3}$ & $\mathbf{0 . 1 1 9 3}$ \\
\hline Corporate Social Responsibility & $\mathbf{3 . 7 4 9 4}$ & $\mathbf{0 . 5 7 0 4 9}$ & $\mathbf{0 . 1 5 2 1}$ \\
\hline
\end{tabular}

Second: Testing the main hypothesis

The main idea of research embodies how much impact of the interactive variable of dynamic capabilities has on the relationship between the two variables, complexity management and strategic performance in terms of direction and strength of that relationship within the approach of the process of continuous improvement of theory. 


\section{Testing the first subhypothesis}

The results of the first subhypothesis of the main hypothesis, in which the environmental sensing capabilities were included as the first dimension of the dynamic capabilities variable dimensions, and according to what is presented in table (4) the reaction limits were added to the model, which confirms the morality of the effect relationship in the financial perspective of the Uncertainty dimensions $.74, \mathrm{P}=0.046=\beta$ ) and dimension diversity management $.82, \mathrm{P}=0.039=\beta$ ) and the interactive dimension of environmental sensing capabilities .99 $\mathrm{P}=0.037=\beta$ ) and dimension of the limit of interaction between diversity management and environmental sensing capabilities $.90, \mathrm{P}=0.038-\beta)$, and the ratio of variance explained in the dimension of financial perspective was indicative of the selection coefficient in the first section $(\mathrm{R} 2=.47)$ and in the second section $(\mathrm{R} 2=50)$ with a positive Direct proportion $(\Delta \mathrm{R} 2=)$, in the selection coefficient, and for the third part of it, the value of the explanatory force of the model as a whole $(\mathrm{R} 2=.52)$ was also a positive Direct proportion $(\Delta \mathrm{R} 2=02)$, These results indicate an interaction of environmental sensing capabilities with the dimensions of the Uncertainty and the diversity management by improving the value of the specificity coefficient .

Table (5) Results of the first subhypothesis test

\begin{tabular}{|c|c|c|c|c|c|}
\hline$\overbrace{\text { Paths Regression (hypotheses }}^{\text {Statistical indicators }}$ & $\begin{array}{l}\text { Regressi } \\
\text { on } \\
\text { paramet } \\
\text { er } \\
\beta\end{array}$ & $\begin{array}{l}\text { Paramet } \\
\text { er Test } \\
\text { Statistics } \\
\text { t } \\
\text { t }\end{array}$ & $\begin{array}{l}\text { Master } \\
\text { 's } \\
\text { morale } \\
\text { Sig }\end{array}$ & $\begin{array}{l}\text { Coefficien } \\
\text { t of } \\
\text { interpreta } \\
\text { tion } \\
\text { R2 }\end{array}$ & $\begin{array}{l}\text { Model } \\
\text { Test } \\
\text { Statistic } \\
\text { S } \\
\text { P }\end{array}$ \\
\hline Interdependence $--\rightarrow$ Financial Perspective & -.22 & $-.598-$ & .551 & \multirow{7}{*}{.52} & \multirow{8}{*}{.000} \\
\hline Uncertainty $---\rightarrow \quad$ Financial Perspective & .74 & 1.973 & .046 & & \\
\hline Diversity Management $\rightarrow$ Financial Perspective & .82 & 2.522 & .039 & & \\
\hline sensing capabilities- $\rightarrow$ Financial Perspective & .99 & 2.107 & .037 & & \\
\hline $\begin{array}{l}\text { Interdependence X sensing capabilities } \\
\rightarrow \text { Financial Perspective }\end{array}$ & .54 & .892 & .374 & & \\
\hline $\begin{array}{l}\text { Uncertainty X sensing capabilities } \\
\rightarrow \text { Financial Perspective }\end{array}$ & -.78 & -1.110 & .269 & & \\
\hline $\begin{array}{l}\text { Diversity X sensing capabilities } \\
\text { Financial Perspective }\end{array}$ & -.90 & -1.180 & .038 & & \\
\hline $\mathbf{R}^{2} \Delta$ & & & & .02 & \\
\hline
\end{tabular}

The form (2) represents the graphical relationship, which shows the effects of the dimensions of the independent variable In the presence of the dimension of the environmental sensing capabilities and their own limits of interaction which described within the first sub-hypothesis of the main hypothesis, the result proves the reactive effect of the dimension of the environmental sensing capabilities in the relationship between complexity management and after the financial perspective, and thus the first subhypothesis can be accepted Partially and within the limits of the moral dimensions only. 
Form (2) The relationship between complexity management dimensions and financial perspective under the interactive impact of environmental sensing capabilities



\section{Test the second sub hypothesis:}

The results of the second sub-hypothesis, in which the opportunity Seize capabilities were included as a second dimension of the dynamic variable dimensions, and according to what is also presented in table (5) the interaction limits were added to the model, which confirmed the morality of the impact relationship in the financial perspective of diversity management dimensions $1.02, \mathrm{P}=\beta$ ) and dimension of interdependence $.41, \mathrm{P}=0.241)$ ) $\beta$ ) and the interactive dimension of opportunity Seize capabilities $1.03 \mathrm{P}=0.033=\beta$ ) and dimension of interaction limit between diversity management and opportunity Seize capabilities $1.21, \mathrm{P}=0.014)-\beta$ ), and the ratio of variance explained in the dimension of financial perspective was indicative of the selection coefficient in the first section $(\mathrm{R} 2=47)$ and in the second section $(\mathrm{R} 2=.51)$ With a positive Direct proportion of $\mathrm{R} 2=04 \Delta$ in the selection coefficient, and for the third part of it, the value of the interpretative force of the model as a whole (R2=.52) was also positive Direct proportion $(\mathrm{R} 2=.01 \Delta)$ these results indicate an interaction of opportunity Seize capabilities with limits To diversity management and interdependence by improving the value of the specificity coefficient.

Table (5) Results of the second sub hypothesis test

\begin{tabular}{|c|c|c|c|c|c|}
\hline Paths Regression (hypotheses & $\begin{array}{l}\text { Regressi } \\
\text { on } \\
\text { paramet } \\
\text { er } \\
\beta\end{array}$ & $\begin{array}{l}\text { Paramet } \\
\text { er Test } \\
\text { Statistics } \\
\text { t } \\
\text { t }\end{array}$ & $\begin{array}{l}\text { Master } \\
\text { 's } \\
\text { morale } \\
\text { Sig }\end{array}$ & $\begin{array}{l}\text { Coefficien } \\
t \quad \text { of } \\
\text { interpreta } \\
\text { tion } \\
\text { R2 }\end{array}$ & $\begin{array}{l}\text { Model } \\
\text { Test } \\
\text { Statistic } \\
\text { S } \\
\text { P }\end{array}$ \\
\hline Interdependence $--\rightarrow$ Financial Perspective & .41 & 1.178 & .241 & \multirow{6}{*}{.52} & \multirow{6}{*}{.000} \\
\hline Uncertainty $---\rightarrow \quad$ Financial Perspective & -.01 & -.035 & .972 & & \\
\hline Diversity Management $\rightarrow$ Financial Perspective & 1.02 & .437 & .016 & & \\
\hline Seize capabilities $\quad-\rightarrow$ Financial Perspective & 1.03 & 2.159 & .033 & & \\
\hline $\begin{array}{l}\text { Interdependence X Seize capabilities } \\
-\rightarrow \text { Financial Perspective }\end{array}$ & -.40 & -.758 & .450 & & \\
\hline $\begin{array}{l}\text { Uncertainty X Seize capabilities } \\
\rightarrow \text { Financial Perspective }\end{array}$ & .37 & .579 & .564 & & \\
\hline
\end{tabular}




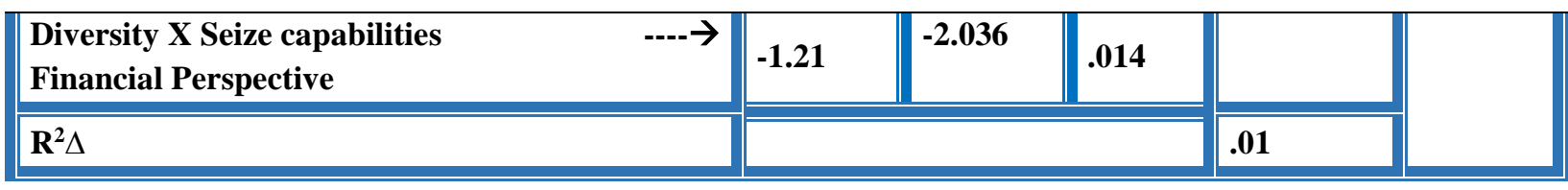

The figure (3) representing this graphical relationship, which shows the effects of the dimensions of the independent variable in the presence the dimension of the environmental sensing capabilities and their own limits of interaction which described within the second sub-hypothesis of the main hypothesis, which proves the results there is a interactive effect of the dimension of environmental sensing capabilities in the relationship between complexity management and financial perspective, and therefore the Second sub-hypothesis can be accepted Partially and within the limits of moral dimensions only.

Form (3) The relationship between complexity management dimensions and financial perspective in light of the interactive impact of the dimension of opportunity Seize capabilities

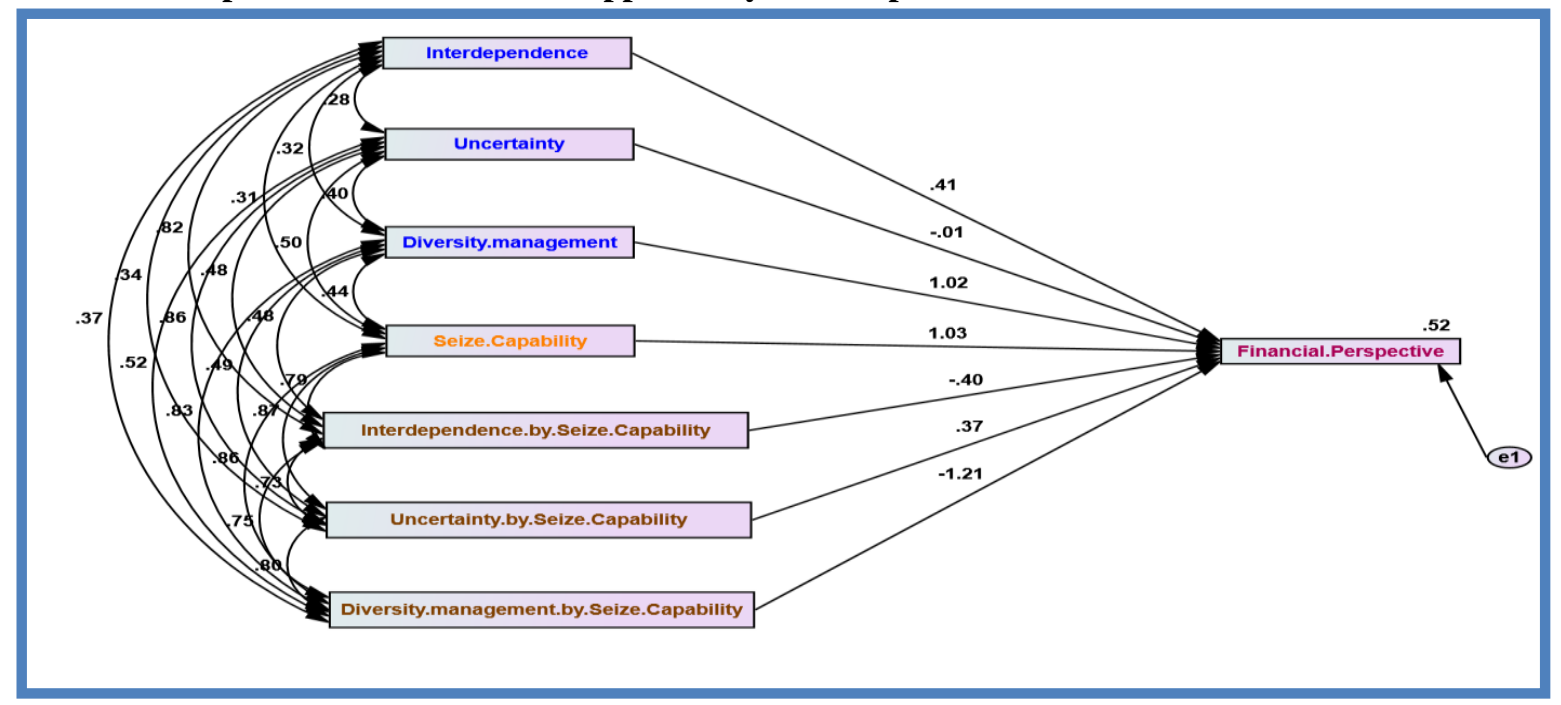

\section{TOPIC 4: DISCUSSING THE RESULTS}

\section{Discussion of results}

The results indicate that dynamic capabilities support and promote resource Reconfigure and the development of new marketing and technological capabilities, which in turn leads to higher competitive performance in terms of market share and profitability. It is assumed that dynamic capabilities such as environmental sensing and opportunity Seize must be effective for achieve high strategic performance. However, organizations are not always in a position to maintain superior profitability or constantly market positions forever. therefore Dynamic capabilities allow organizations not only to employ their strategic capabilities in more effective ways, but also to renew and Reconfigure them in order to address the challenges of environmental changes in terms of Interdependence and uncertainty. The results are also assumed to be considered in view of previous research, which assumes a potentially positive impact of dynamic capabilities on overall performance and strategic performance particularly, variable of the financial perspective, and finally, this confirms that dynamic capabilities have a positive impact on the complexity management and strategic performance even in a relatively stable environment. 


\section{REFERENCES}

\section{$\underline{\text { A.Books }}$}

1. Brocke, Jan vom \& Rosemann, Michael. (2015). Handbook on business process management 1: Introduction, methods, and information systems .

2. Carton, R. B., \& Hofer, C. W. (2006). Measuring organizational performance: Metrics for entrepreneurship and strategic management research. Edward Elgar Publishing.

3. Davila, A., \& Elvira, M. M. (2012). Understanding Organizations in Complex, Emergent and Uncertain Environments: An Introduction. In Understanding Organizations in Complex, Emergent and Uncertain Environments. Palgrave Macmillan, London.

4. Edgeman, R. (2019). Complex Management Systems and the Shingo Model: Foundations of Operational Excellence and Supporting Tools. CRC Press.

\section{B. Journals \& Periodical}

1. Antinyan, V., Sandberg, A. B., \& Staron, M. (2019). A Pragmatic View on Code Complexity Management. Computer,Vol.52,NO.2,PP.14-22.

2. Abdul Majid,Z.Y., (2016),"Strategic performance through inter-firm networks: strategic alignment and moderating role of environmental dynamism", World Journal of Entrepreneurship, Management and Sustainable Development, Vol.12,No.4 pp.282-298.

3. Darawong, C. (2018). Dynamic capabilities of new product development teams in performing radical innovation projects, International Journal of Innovation Science, Vol.10,No.3,PP.333-349.

4. Deya, J. (2016). Relationship between dynamic capabilities and competitive advantage of Technical, Vocational and Entrepreneurship Training Institutions in Kenya (Doctoral dissertation, Business Administration (Strategic Management), JKUAT).

5. Dong, X., Andrew Hinsch, C., Zou, S., \& Fu, H. (2013). The effect of market orientation dimensions on multinational SBU's strategic performance. International Marketing Review, 30(6), 591-616.

6. Dutta, K. (2019). Exploring dynamic capabilities: A systems thinking approach. Systems Research and Behavioral Science,Issue (February),PP1-12.

7. Furnival, J., Boaden, R., \& Walshe, K. (2019). A dynamic capabilities view of improvement capability. Journal of Health Organization and ManagementVol.33,No.(7-8),PP.821-834.

8. Hassan, H., Maelah, R., \& Amir, A. M. (2016). Strategic performance measurement and managerial performance: the mediating role of job satisfaction and psychological empowerment. Journal of Contemporary Issues and Thought, Vol.6,No.2003,PP.47-63.

9. Karimi-Alaghehband, F., \& Rivard, S. (2020). IT outsourcing success: A dynamic capability-based model. The Journal of Strategic Information Systems, Vol.29,No.1,PP.101599.

10. Karuhanga, B. N. , (2015), "Evaluating implementation of strategic performance management practices in universities in Uganda", Measuring Business Excellence,Vol.19,No.2,pp.42-56.

11. Khaireddin, M., Assab, M. I. A., \& Nawafleh, S. A. (2015). Just-in-Time Manufacturing practices and Strategic Performance: An Empirical Study Applied on Jordanian Pharmaceutical Industries. International Journal of Statistics and Systems, Vol.10,No.2,PP.287-307.

12. Kostopoulos, I., Boukis, A., \& Lodorfos, G. (2019). Conceptualizing and Measuring Perceived Service Complexity. Journal of Marketing Theory and Practice,Vol.27,No.1,PP. 38-54 .

13. Kryvinska, N., Hacker, T. J., Xhafa, F., \& Alexander, M. (2014). Flexible Complexity Management and Engineering by Innovative Services.Global Journal of Flexible Systems Management,Vol.15,No.1,PP.1-3.

14. Lamarche, P., \& Maillet, L. (2016). The performance of primary health care organizations depends on interdependences with the local environment. Journal of Health Organization and Management,Vol.30,No.6,PP.836-854. 
15. Meng, Y., \& Sun, Q. (2019, December). Path Analysis of Building Organizational Dual Abilities from the Perspective of Dynamic Capability Theory. In 5th Annual International Conference on Social Science and Contemporary Humanity Development, Atlantis Press,Vol.376,No.(Sschd),PP.509-515.

16. Oyewobi, L. O., Windapo, A. O., \& Rotimi, J. O. B. (2015). Measuring strategic performance in construction companies: a proposed integrated model. Journal of Facilities Management,Vol.13,No.2,PP.109-132.

17. Pollanen, R., Abdel-Maksoud, A., Elbanna, S., \& Mahama, H. (2016). Relationships between strategic performance measures, strategic decision-making, and organizational performance: empirical evidence from Canadian public organizations. Public Management Review,Vol.19,No.5,PP.725-746.

18. Reim, W., Parida, V., \& Örtqvist, D. (2015). Product-Service Systems (PSS) business models and tactics - A systematic literature review. Journal of Cleaner Production.Vol.97,No.(october2015),PP.61-75 .

19. Rusydi, M., Naidah, N., \& Sulaiman, S. (2019). THE ROLE OF DYNAMIC CAPABILITY IN IMPROVING EXPORT COMPANIES'COMPETITIVENESS AND PERFORMANCE. SEIKO: Journal of Management \& Business, Vol.3,No.1,PP.83-100.

20. Schilke, O. (2013). On the contingent value of dynamic capabilities for competitive advantage: The nonlinear moderating effect of environmental dynamism. Strategic Management Journal, Vol.35,No.2,PP.179-203.

21. Schütz, K., Kässer, M., Blome, C., \& Foerstl, K. (2019). How to achieve cost savings and strategic performance in purchasing simultaneously: A knowledge-based view. Journal of Purchasing and Supply Management,Vol.26,No.2,PP.1-52 .

22. Snihur, Y., \& Tarzijan, J. (2017). Managing complexity in a multi-business-model organization. Long Range Planning,Vol.51,No.1,PP.50-63.

23. Sundström, A., \& Ahmadi, Z. (2019). The Mediating Role of CSR on the Market Orientation and Strategic Performance Relationship_A Study of the Public Housing Companies in Sweden. Sustainability,Vol.11,No.6,PP.1-18.

24. Teece, D. J. (2016). Dynamic capabilities and entrepreneurial management in large organizations: Toward a theory of the (entrepreneurial) firm. European Economic Review, Vol.86,PP.202-216.

25. Tong, Y. K., \& Arvey, R. D. (2015). Managing complexity via the Competing Values Framework. Journal of Management Development,Vol.34,No.6,PP.653-673.

26. Wiengarten, F., Ahmed, M. U., Longoni, A., Pagell, M., \& Fynes, B. (2017). Complexity and the triple bottom line: an information-processing perspective. International Journal of Operations \& Production Management,Vol.37,No.9,PP.11421163 .

27. Yadav, N., \& Sagar, M. (2013). Performance measurement and management frameworks. Business Process Management Journal,Vol.19,No.6,PP.947-971.

28. Zou, W., Brax, S. A., Vuori, M., \& Rajala, R. (2019). The influences of contract structure, contracting process, and service complexity on supplier performance. International Journal of Operations \& Production Management,Vol.36,No.4,PP.525-549. 